\title{
Cross-laminated Timber Tornado Safe Room as a Stand-alone Module
}

\author{
Jose Daniel CANDELARIO ${ }^{1,3} *$, Sylvain GAGNON² \\ ${ }^{1}$ M.Sc., Jr. Eng., Researcher - Advanced Building Systems, FPInnovations \\ ${ }^{2}$ Eng., Acting Researcher Leader - Advanced Building Systems, FPInnovations \\ ${ }^{3}$ Corresponding author's e-mail: josedaniel.candelario@fpinnovations.ca
}

\begin{abstract}
A tornado safe room is typically a small interior room such as an office or a bathroom which is strengthened in order to provide occupants with near-absolute protection during extreme loading events such as tornadoes. The loads associated with extreme wind loading events are generally in the form of wind induced pressures or impact loading from windborne debris. These rooms are designed to be structurally independent so as to maintain their integrity given the destruction of the surrounding structure. Prefabrication of such rooms as a stand-alone module can be an important advantage since the proper installation of the connection system is particularly critical to its structural performance. Furthermore, the safe room may be fabricated with utility services such as plumbing, electrical, and HVAC systems.

Cross-laminated Timber (CLT) is an innovative engineered wood product that has been increasingly used in building construction over the past decade. It is a massive timber slab with excellent strength and stiffness properties as well as remarkable fabrication precision and dimensional stability. In this study, the feasibility and potential for a modular tornado safe room constructed out of CLT panels is discussed. Such structures may represent viable solutions for difficulties associated with residential safe room construction providing a safe, more sustainable, and potentially economic alternative to conventional systems.
\end{abstract}

\section{KEYWORDS}

Cross-laminated Timber (CLT); Modular; Pre-fabricated; Tornado Shelters; Safe Room

\section{INTRODUCTION}

Residential safe rooms generally consist of a strengthened interior room which is structurally independent from the rest of the structure. The concept first arose in 1974 [1] following observations of small interior rooms left standing upon the destruction of the surrounding low rise building as shown in Figure 1. This type of in-home shelter presents several advantages to the traditional underground bunker type storm shelter such as ease 
of access and usability of space since the safe room can double as a walk-in closet, bathroom or small office.

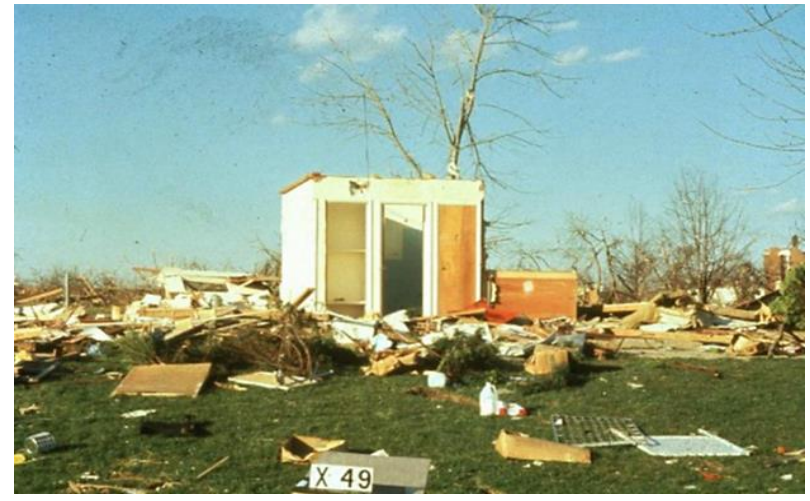

Figure 1. Interior room left standing upon the destruction of the surrounding structure (image credit: FEMA)

Safe rooms are structures that have been strengthened in order to provide occupants with "near-absolute protection" during extreme wind loading events such as hurricanes and tornadoes. Resistance requirements associated with extreme wind loading events may be due to wind-induced pressures or impact loading from windborne debris.

Cross-laminated timber (CLT) is a relatively new engineered wood product first developed in Austria and Germany in the nineties. Over the past decade however, CLT has experienced a significant growth in North America. As with any new product causing an impact in the construction industry, a process of experimentation and innovation is a necessary step towards determining the applications that can best benefit from the product's characteristics.

For now, CLT is predominantly being used in mid-rise construction ( 5 to 8 stories) due to the easy handling and the high level of prefabrication and precision resulting in significantly reduced erection times when compared with conventional systems [2].

\section{RESIDENTIAL SAFE ROOMS}

The F5 tornado in Moore, Oklahoma on May 3, 1999 was the starting point of a market penetration of tornado shelters in metropolitan areas [3]. This movement was also accompanied by the interest of the general public and policy makers as reflected by rebate programs such as the Oklahoma Safe Room Initiative. In addition, the Federal Emergency Management Agency (FEMA) has launched rebate programs to increase market penetration of tornado shelters in several states in the 'Tornado Alley' of the United States such as Alabama, Arkansas, Oklahoma, Iowa, and Mississippi. Additional rebate programs for the design of hurricane and tornado shelters have been also implemented in the state of Florida. All these initiatives are directed towards the 
construction of permanent homes. In the preface of FEMA 320 Taking Shelter from the Storm [4], it is said that since 1998 more than 20,000 residential safe rooms have been built in the USA with federal funding initiatives. It is also estimated that other tens of thousands of safe rooms have been constructed with private funding. However, there is a general perception that violent tornado events are just too rare to render tornado resistant structures cost effective [3].

\section{Structural Requirements}

Residential buildings are seldom designed to resist tornadic winds due to the cost increase this would represent in contrast with the low probability that the structure will be submitted to such event. Tornado shelters have been traditionally used in tornado-prone regions in order to prevent death or injury of occupants despite the collapse of the main structure. These, however, were generally located underground, and sometimes only accessible from the exterior of the house. More modern versions of residential tornado shelters are termed safe rooms because they basically have the form of a typical room in a house such as a bathroom or a laundry, the difference being that they are detailed to be structurally independent. The safe room structure is then designed for wind-induced loading exceeding that of the rest of the residence so as to maintain its integrity even after the surrounding structure has completely failed as shown in the schematic in Figure 2. In this way, the high costs associated with designing a 'tornado resistant' structure are limited to only one of the residence's rooms while providing a high level of safety to the occupants.

There are many advantages of a safe room over the traditional underground tornado shelter or bunker. The accessibility is significantly improved, which is extremely important due to the intense and unpredictable nature of tornados. Furthermore, an abovegrade safe room is less prone to flooding due to the heavy rain that is generally associated with storm events. Another important benefit is that the space may be used in everyday life by the occupants, meaning that even if it is never used as a safe room, it can represent a valuable space. Moreover, if the safe room is designed as a bathroom it provides access to water supply and a toilet.
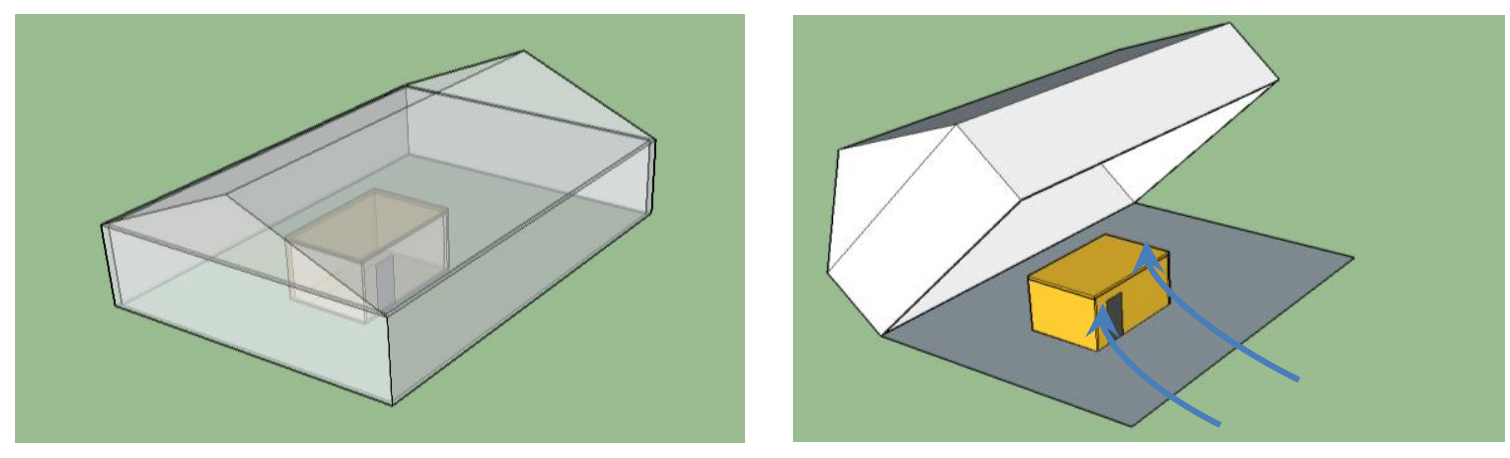

Figure 2. Structural performance principle behind residential safe rooms 
The International Code Council (ICC) in collaboration with the National Storm Shelter Association (NSSA) published the ICC/NSSA Standard for the Design and Construction of Storm Shelters (ICC-500) [5]. Two documents FEMA 320 and FEMA 361 [6] were used as the basis for the development of the ICC-500. In terms of structural design loads, compliance with ASCE 7-10 [7] for a design wind speed of 250mph $(111.8 \mathrm{~m} / \mathrm{s})$ is required for the tornado alley region of the United States. The most common failure modes for a safe room due to wind-induced loading are presented in Figure 3.
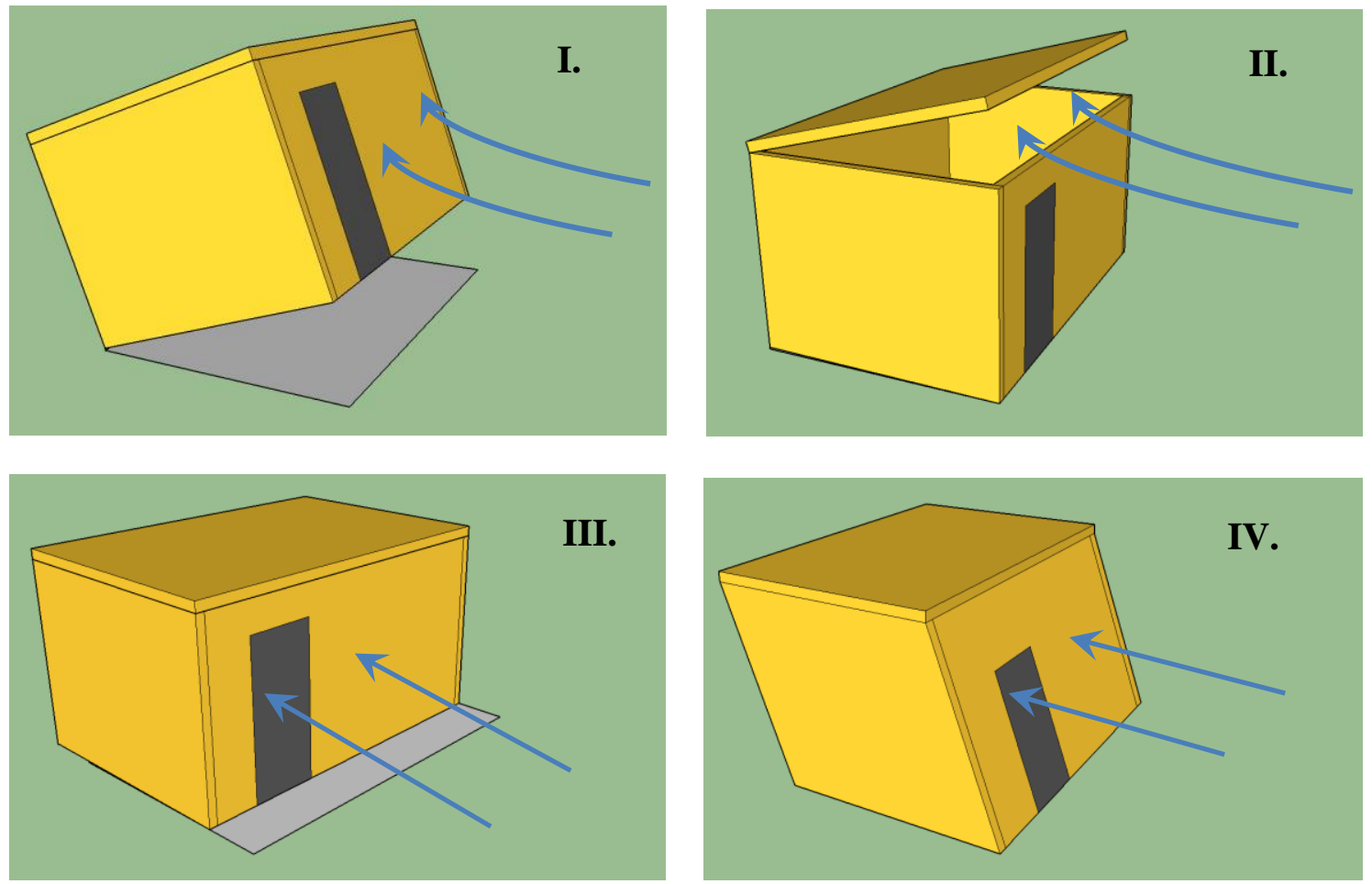

Figure 3. Failure modes associated with safe rooms under wind-induced loading: I. Over turning; II. Roof uplifting; III. Base shear IV. Racking

In addition to the wind-induced loading design every component is required to resist the impact of a $15 \mathrm{lb}(33 \mathrm{~kg}) 2 \mathrm{x} 4$ dimension lumber element travelling horizontally at $100 \mathrm{mph}(44.7 \mathrm{~m} / \mathrm{s})$. The specific testing procedure is presented in Chapter 8 of ICC 500 and is intended to represent a common projectile encountered in a tornado travelling at a speed caused by a $250 \mathrm{mph}(111.8 \mathrm{~m} / \mathrm{s})$ wind.

\section{Advantages of CLT for Safe Room Construction}

Cross-laminated Timber (CLT) panels are made up of several layers of dimension lumber stacked at $90^{\circ}$ angles and glued together along their broad faces in order to form a solid slab as shown in Figure 4. CLT is generally fabricated with three to seven orthogonal layers often referred to as plies. The cross-lamination of the plies gives the panel exceptional in-plane and out-of plane structural performance in both directions. The 
cross-lamination of the timber elements also increases significantly the splitting resistance of the material for several types of connection systems and loading conditions.
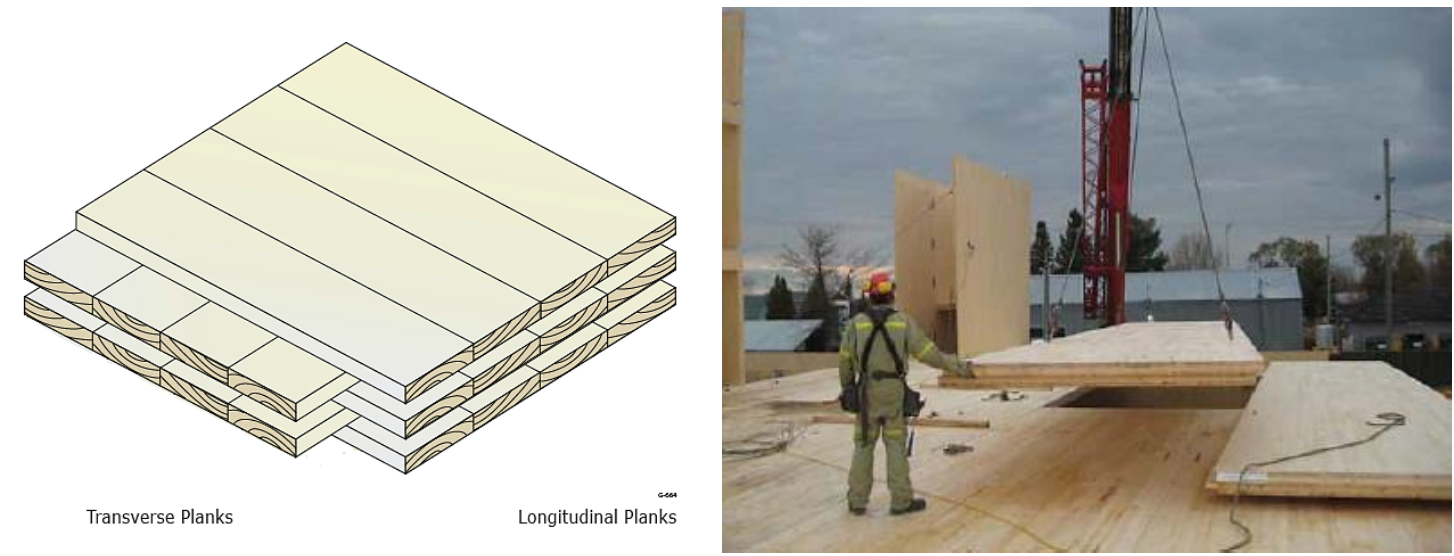

Figure 4. Cross-laminated Timber panel configuration (image credit: CLT Handbook)

The Forest Product Laboratory of the USDA has performed some preliminary impact testing on 5-ply CLT panels [8]. It may be observed in Figure 5 that despite some marked damage of the CLT panel, there is no piercing of through of the stud. This demonstrates the adequate performance of a 5-ply CLT for use as a storm shelter envelope. Further testing is required to evaluate the performance of a 3-ply CLT panel, as this may result in a more efficient design.

In terms of the wind-induced loadings, a study was undertaken at FPInnovations (FPInnovations, unpublished manuscript 2014) in which the forces on a residential safe room with $10^{\prime} \times 10^{\prime}(3 \mathrm{~m} \times 3 \mathrm{~m})$ floor plan dimensions and a $8^{\prime}(2.4 \mathrm{~m})$ height were determined in accordance with ASCE $7-10$ for $250 \mathrm{mph}(111.8 \mathrm{~m} / \mathrm{s})$ winds. It was concluded that the strength properties in a 3-ply CLT panel satisfactorily meet the demands of these extreme wind-induced pressures, and that the integrity of the structure would therefore rely on the design of the connections. 

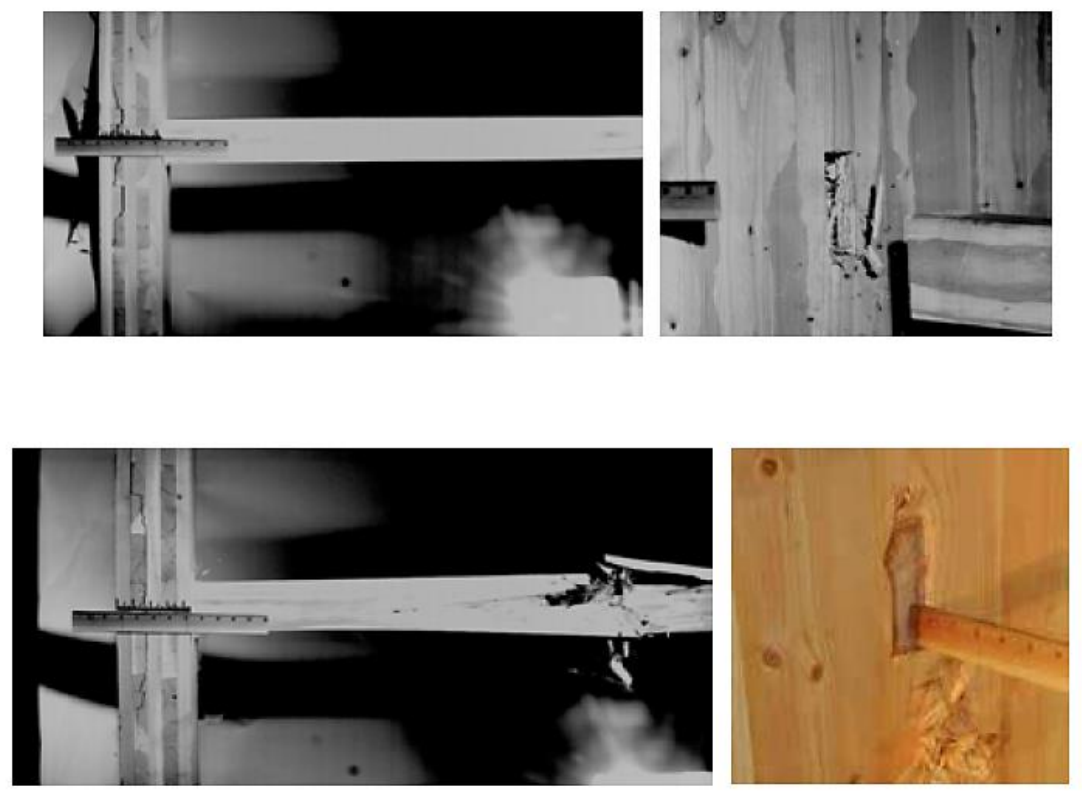

Figure 5. Impact testing on 5-ply Douglas fir CLT (Source: Birdwell et al., 2013)

The required resistances of the connections were then compared to the performance exhibited by fasteners currently employed for CLT in mid to high-rise construction for the four failure modes presented in Figure 3. It was concluded that using widely tested connection systems such as continuous anchors for over turning resistance, and selftapping screws for roof-to-wall and wall-to-wall connections, the resistance requirements could be easily met. Some details of such connections are available in [2].

An additional advantage of constructing with CLT lies in the environmental impacts in comparison with other construction systems. CLT is expected to have a lighter carbon footprint, due to low greenhouse gas emissions, and due to the carbon storage capacity of wood products. However, research in this field is still in the preliminary stages [2]. When compared with traditional light wood frame construction, the environmental benefits are less evident. However, light wood frame construction for FEMA-compliant safe rooms is not an option since the impact testing requirements stated in ICC 500 would not be met by plywood panels alone. In general, FEMA recommends a combination of plywood and welded mesh fabric, or concrete masonry units (CMU).

\section{Advantages of Modular CLT Tornado Safe Rooms}

Several builders have begun exploring the possibilities of CLT in modular construction mainly for mid-rise buildings (see Figure 6). The high strength and rigidity of the CLT panels facilitate the design of modules that can be easily transported, lifted, and placed on site while maintaining their integrity without requiring any additional reinforcement considerations. Additionally, several other advantages may be expected for the modular construction of CLT safe rooms proposed in this study. 
By incorporating utilities into the CLT safe room module, gains in terms of construction times may be achieved. Designs can be made to contain the buildings utility core with fittings for common services such as water, sewer, electrical, HVAC, and computer network or phone settings. The safe room modules would include the necessary connectors to allow for rapid coupling of the wiring or plumbing sources. During everyday use, the space may serve the function of a bathroom or laundry room. Including utilities into the safe room module may represent gains in construction time by simplifying some of the more technical aspects of residential construction and avoiding typical problems such as conflicting utilities.

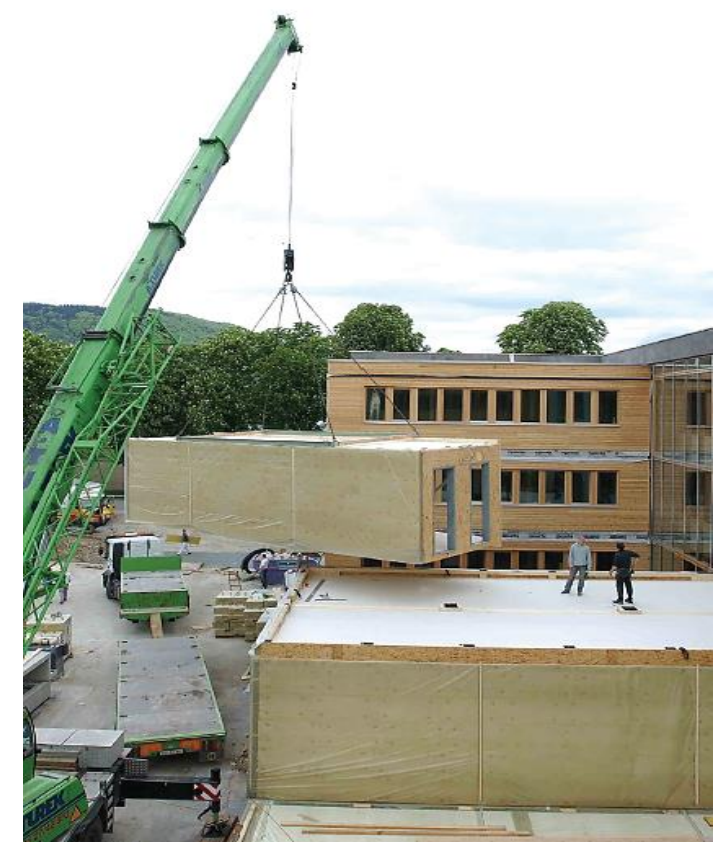

Figure 6. Modular construction of a 4-story CLT building in Austria, curtesy of KLH (source: CLT Handbook)

Another important advantage of the modular CLT safe room may reside in the quality control. As was previously stated, the structural performance of a CLT safe room will be primarily dependent on the resistance of the connection system. If constructed offsite as an independent module, the fastening systems responsible for preventing modes of failure II and IV (as described in Figure 3) can be assembled in a controlled environment. Adhesives which are generally not allowed for on-site construction may be used to provide additional stiffness to the system.

\section{CONCLUSION}

It can be said that over the last decade there has been a growing market for residential safe room construction, particularly in the tornado prone regions of the United States due to several catastrophic events and the resulting economic aid initiatives. Furthermore, the 
use of safe rooms can be made more attractive to the public if a reduction in costs and economic impacts are associated to such systems.

The potential for Cross-laminated Timber (CLT) for such structures in order to comply with the loading requirements established in ICC 500 have been presented, along with the potential advantages that may result from fabricating the safe rooms as a stand-alone module. This could serve as a step in exploring the possible advantages of larger modular construction with CLT. Prefabricated CLT modules with integrated utilities might also prove to be effective for use with mid-rise and high-rise residential construction.

\section{ACKNOWLEDGEMENTS}

The authors would like to express their deep gratitude to Natural Resources Canada (NRCan) for providing the funding under the Transformative Technologies program which made this study possible.

\section{REFERENCES}

[1] Kiesling, E. W., and Goolsby, D. E. (1974). "In-home shelters from extreme winds." Civil Engineering, 44(9), 105-107.

[2] Gagnon, S. and C. Pirvu, eds. 2011. CLT Handbook: Cross-laminated timber. Canadian ed. Special Publication SP-528E. Québec, QC: FPInnovations. 1v.

[3] Merrell, D., Simmons, K., Sutter, D. (2005). "The Determinants of Tornado Casualties and the Benefits of Tornado Shelters." Land Economics, 81(1):87-99. Ipswich, MA.

[4] FEMA (2008). "FEMA P-320 Taking Shelter From the Storm: Building a Safe Room For Your Home or Small Business." Federal Emergency Management Agency.

[5] ICC (2008). "ICC-500 Standard for the Design and Construction of Storm Shelters." International Code Council.

[6] FEMA (2008). "FEMA P-361 Design and Construction Guidance for Community Safe Rooms." Federal Emergency Management Agency

[7] ASCE (2010). "Minimum design loads for building and other structures." American Society of Civil Engineers, ASCE Preston Virginia Virginia.

[8] Bridwell, J. J., Ross, R. J., Cai, Z., and Kretschmann, D. E. (2013). "USDA Forest Products Laboratory's Debris Launcher." USDA Forest Service, Forest Products Laboratory. 